Published in final edited form as:

Asia Pac J Public Health. 2015 March ; 27(2): NP194-NP202. doi:10.1177/1010539511433049.

\title{
Epidemiological associations of vision impairment and health among a national cohort of 87,134 adults in Thailand
}

\author{
Vasoontara Yiengprugsawan, PhD, \\ National Centre for Epidemiology and Population Health, The Australian National University, \\ Canberra, Australia \\ Sam-ang Seubsman, PhD, \\ School of Human Ecology, Sukhothai Thammathirat Open University, Nonthaburi, Thailand \\ Adrian C Sleigh, MD, and \\ National Centre for Epidemiology and Population Health, The Australian National University, \\ Canberra, Australia
}

\section{Thai Cohort Study Team ${ }^{\dagger}$}

\begin{abstract}
To date, over 300 million people worldwide live with low vision and blindness, imposing social and economic burdens on individual and families. Data derived from a cohort of 87,134 Thai adults. We report Odds Ratios (ORs) from logistic regression and derive Population Attributable Fractions (PAFs). Approximately 28\% of the cohort members reported refractive errors and $8 \%$ had uncorrectable vision impairment. Awareness of refractive errors was associated with higher income and urban residence. Both types of vision impairment were positively associated with poor self-assessed health (adjusted ORs 1.23 to 2.03) and poor psychological health (adjusted ORs 1.13 to 1.63). PAFs show that correctable and uncorrectable vision impairments explain respectively $6.1 \%$ and $7.5 \%$ of poor self-assessed health, $3.5 \%$ and $4.7 \%$ of poor psychological health, and $2.2 \%$ and $3.1 \%$ of falls in the last year. Incorporating early detection and prevention at the primary healthcare level will help to promote the health of Thais.
\end{abstract}

\section{Keywords}

vision impairment; self-assessed health; injury; falls; cohort study; Thailand

\footnotetext{
Address to Correspondence: Dr. Vasoontara Yiengprugsawan, The Australian National University Building 62 - National Centre for Epidemiology and Population Health, Acton 2601, Canberra, Australia. Tel: +61 2 6125 2378; Fax: +61 2 6125 0740;

yasoontara.yieng@anu.edu.au, vasoontara.yieng@gmail.com.

†Thai Cohort Study Team

Thailand: Jaruwan Chokhanapitak, Chaiyun Churewong, Suttanit Hounthasarn, Suwanee Khamman, Daoruang Pandee, Suttinan Pangsap, Tippawan Prapamontol, Janya Puengson, Yodyiam Sangrattanakul, Sam-ang Seubsman, Boonchai Somboonsook, Nintita Sripaiboonkij, Pathumvadee Somsamai, Duangkae Vilainerun, Wanee Wimonwattanaphan. Australia: Chris Bain, Emily Banks, Cathy Banwell, Bruce Caldwell, Gordon Carmichael, Tarie Dellora, Jane Dixon, Sharon Friel, David Harley, Matthew Kelly, Tord Kjellstrom, Lynette Lim, Roderick McClure, Anthony McMichael, Tanya Mark, Adrian Sleigh, Lyndall Strazdins, Vasoontara Yiengprugsawan.

Competing interests

The authors declare that they have no competing interests.
} 


\section{Background}

Approximately 314 million people worldwide live with low vision and blindness from all causes; of these, 45 million people are blind and 269 million have low vision. ${ }^{1}$ Globally, the leading causes of blindness include cataract, uncorrected refractive errors, glaucoma, macular degeneration, corneal opacity, and trachoma. Without prevention or early detection and treatment, these conditions will all remain important causes of blindness in developing countries. ${ }^{2,3}$ Uncorrected refractive errors, estimated to affect 123 to 184 million people worldwide, hamper performance at school, reduce employability and productivity, and impair quality of life. The global increase in the size of the elderly population presents a further challenge. In 1999, WHO launched 'Vision 2020', a global initiative to eliminate avoidable blindness.

In the past decade, several large population based studies have provided new information on the prevalence of visual impairment and the major age related eye diseases and some of these studies have related to Asia. ${ }^{4-7}$ In Thailand, it is expected that by 2020 there will be 10.8 million people aged over 60 years, twice as many as in $1998 .{ }^{8}$ Blindness and visual impairment are major causes of disability among the Thai elderly and are emerging problems that accompany aging. ${ }^{8-11}$ Cataract, glaucoma, refractive error, diabetic retinopathy and age related macular degeneration are frequently found in the elderly; as well, refractive errors are notable problems for children and working adults. For the past few decades, the Thai National Programme for Prevention of Blindness and Eye Health Promotion has focused on children, working adults and the elderly.

In past years, there have been studies showing a link between visual impairment and higher mortality ${ }^{12}$ and worse self-rated health and psychological health among elderly persons. ${ }^{13-17}$ As well, one study reported on poor visual function in working-age adults and associations with early life influences and eventual adverse health and social outcomes. ${ }^{18}$ There is also evidence of increased adverse health effects with concurrent hearing and vision impairments. ${ }^{19,20}$

Our study examines all-cause visual impairment (refractive errors and vision not correctable by glasses) and associated adverse health outcomes based on a national cohort of 87,134 Thai adults. The results of this study provide insights into the public health implications of these conditions and provide information needed to promote healthy vision among working Thais.

\section{Methods}

\section{Study population and data collection}

Data were derived from a cohort of 87,134 distance learning students aged 15 to 87 years enrolled at Sukhothai Thammathirat Open University (STOU) who completed a baseline study in 2005. The baseline characteristics of cohort participants compared to the population of Thailand has been reported. ${ }^{21}$ The baseline questionnaire covered a wide range of topics including demographic, socioeconomic and geographic characteristics, health status, health service use, risk behaviours, injuries, dietary intake, physical activities, transportation, and 
family background. A four-year follow-up was conducted in 2009 and the next one is due in 2013. Here we analyse the visual status and relate that to age, sex, income, lifecourse urbanization, and health outcomes.

\section{Measures of vision impairment}

Two questions related to vision impairments were as follows:

Refractive errors: "Which statement best describes your current eyesight?" Response categories were: 'I do not need glasses'; 'I need glasses or contact lenses since childhood < 13 years old'; 'I need glasses or contact lenses since a teenager 13-19 years old'; 'I need glasses or contact lenses since adulthood 20 years old or more'.

A second question asked: "Do you currently have any sight problems not correctable by glasses or contact lenses (eg. cataract)". Response categories were: 'yes' or 'no'.

\section{Measures of health outcomes}

Four health outcomes were assessed for their relationship to vision impairment psychological health, self-rated health, injury, and falls.

Psychological health was assessed using three items of the standard Kessler psychological distress questions ${ }^{22}$ : "In the past 4 weeks, about how often did you feel: 1) nervous; 2) restless or fidgety; 3) everything was an effort". Those answering 'all the time' or 'most of the time' on all questions were classified as having 'poor' psychological health.

Overall self-rated health is based on the first question of the Medical Outcomes Short Form instrument "Overall how would you rate your health during the past four weeks?" (excellent, very good, good, fair, poor, or very poor). For analysis, we combined the last two categories as 'poor or very poor' self-assessed health.

Overall injury was assessed by the question: "In the last 12 months, have you had injuries that were serious enough to interfere with daily activities and/or required medical treatment?"

Falls were assessed by asking "If not a traffic injury, what was the circumstance?" 'Fall' was one of the responding categories.

Potential confounders tested for influence on vision impairment included doctor diagnosed diabetes and hearing impairment. The hearing question was "Which statement best describes your current hearing (without a hearing aid)?" Those who responded 'some trouble and deaf' were then categorized as 'poor hearing'. Our analysis of hearing impairment has been reported elsewhere. ${ }^{23}$ Other variables considered here with potential to confound assessments included age, sex, monthly income and lifecourse geographical residence.

\section{Data processing and statistical analysis}

Data scanning and editing were done using Thai Scandevet, SQL and SPSS software. For analysis we used Stata version 11. Individuals with missing data for analyses presented here were excluded so totals vary a little according to the information available. Missing data 
usually involved $1 \%$ or less of observations and given the large size of our dataset, our results were stable.

We assessed the association between health outcomes (self-assessed health, psychological health, injury and falls) and potential determinants (refractive errors and vision impairment not correctable by visual aids) using logistic regression models presenting Odds Ratios (ORs) and 95\% Confidence Intervals (CI), adjusting for age, sex, income, lifecourse residence, hearing impairment and metabolic disorders (doctor-diagnosed diabetes type I and II and high cholesterol).

We also calculate Population Attributable Fractions (PAF) - the proportion of all cases of a given related adverse health outcome that occurred in the study population and could have been avoided if no one had the vision impairment. PAFs were calculated from the age-sex adjusted odds ratios and the prevalence of vision impairment among the general population as represented by the cohort as a whole. We used the following formula to calculate the PAF: 24

$$
P A F=\frac{\text { Prevalence of exposure }(\text { Odds ratios }-1)}{\text { Prevalence of exposure }[(\text { Odds ratios }-1)]+1}
$$

\section{Ethical considerations}

Ethics approval was obtained from Sukhothai Thammathirat Open University Research and Development Institute (protocol 0522/10) and the Australian National University Human Research Ethics Committee (protocol 2004344). Informed written consent was obtained from all participants.

\section{Results}

\section{Characteristics of the cohort members}

There were 87,314 cohort members analysed and slightly more than half were females (54.7\%). Age ranged from 15-19 years (2.9\%), 20-29 years (50.8\%), 30-39 years (31.3\%), $40-49$ years $(12.6 \%)$ and 50 years or older (2.5\%). Approximately $40 \%$ of cohort members reported income per month of less than 7000 Baht (about US $\$ 175$ in 2005); 22.7\% reported between 7000 and 10000 Baht; and 34.0\% reported more than 10000 Baht per month. Three groups of lifecourse urbanization were reported: rural residents (43.3\%); rural moved to urban areas since age 12 years (31.5\%); and urban residents $(25.2 \%)$.

\section{Vision impairment and health outcomes}

Refractive errors-eyesight correctable by glasses or contact lenses-were reported by $28.1 \%$ and an additional $7.9 \%$ reported eyesight problems not correctable by any visual aids (Table 1). Females were more likely to report refractive errors than males as children or adolescents but the proportions affected were similar in adulthood. Those needing glasses or contact lenses as adults substantially increased with age: $18.5 \%$ for those aged 30-39 years, $47.6 \%$ for those aged $40-49$ years, and $71.1 \%$ for those aged more than 50 years. There were income gradients in reporting refractive errors since adulthood: $13.5 \%$ among those with 
income less than 7000 Baht per month; 19.6\% among those earning between 7,000 and 10,000 Baht per month; and 31.4\% among those earning more than 10,000 Baht per month. Cohort members currently residing in urban areas were more likely than their rural counterparts to report refractive errors or eyesight problems not correctable by glasses or contact lenses.

\section{Association between vision impairment and health outcomes of cohort members}

Compared with those reporting no vision impairment, those with either type of vision impairment (correctable and not correctable) were more likely to report poor self-assessed health $(4.0 \%$ for no impairment vs $6.0 \%$ for correctable impairment and $7.8 \%$ for uncorrectable impairment) (Table 2). The results were similar for poor psychological health (5.6\% vs $6.9 \%$ vs. $8.9 \%)$. Those with correctable or uncorrectable vision impairment were also more likely than the unimpaired to report poor hearing ( $7.2 \%$ vs. $12.2 \%$ vs. $14.1 \%$ ). Metabolic disorders were also more common among those who reported either type of vision impairment. Overall injuries and falls were also more common among those with vision impairments.

As was noted from distribution data being female and of older age were both likely to influence vision impairment, so analyses were adjusted for age, sex, monthly income, lifecourse urbanization, poor hearing and metabolic disorders (Table 3). Both types of vision impairment (refractive errors and uncorrectable by visual aids) were associated with poor self-assessed health $(\mathrm{OR}=1.23 ; 95 \%$ CI $1.32-1.55 ; \mathrm{OR}=2.03 ; 95 \%$ CI $1.85-2.25)$ and poor psychological health $(\mathrm{OR}=1.13 ; 95 \% \mathrm{CI} 1.04-1.22 ; \mathrm{OR}=1.6395 \% \mathrm{CI} 1.46-1.81)$. Also, both types of vision impairment were positively associated with overall injuries, especially the risk of falls.

Analysis of Population Attributable Fractions (Table 4) reveal that refractive errors and vision impaired not correctable by visual aids contributed to PAFs of $6.1 \%$ and $7.5 \%$ of poor self-assessed health; and $3.5 \%$ and $4.7 \%$ of poor psychological health. These visual impairments also can be attributed to respectively $2.2 \%$ and $3.1 \%$ of falls in the last 12 months.

\section{Discussion}

Females were more likely than males to report refraction errors correctable by glasses or contact lenses. Vision impairments had even more pronounced association with increasing age. Refractive errors were much more likely to be reported by those with higher incomes and were also more likely in urban areas, but neither factor had much influence on the prevalence of non correctable vision impairments. Our cohort data also revealed a strong relationship between both types of vision impairment and poor self-assessed and poor psychological health. Uncorrectable vision impairment was also associated with overall injuries and falls in the past 12 months. The Population Attributable Fraction analysis takes into account both the strength of the association and the prevalence of one or other category of vision impairment. The PAFs revealed that a substantial proportion of poor overall health and poor psychological health can be attributed to refractive error (about 10\%) and a smaller 
proportion can be attributed to uncorrectable vision impairment (6-9\%). About $4 \%$ of falls and $1-3 \%$ of injuries were attributable to vision impairments.

These results were supported by other Thai studies among elderly. ${ }^{25,26}$ For example, a study based on almost 600 elderly individuals found that only $12 \%$ of the elderly had regular eye check ups at least once a year, $65 \%$ sought a check up service only when they experienced visual loss and $10 \%$ had eye glasses. ${ }^{8}$ Our study also supported other studies on vision impairment and various adverse health outcomes, for example, visual sensory impairments were significantly associated with increased risk for depression (OR 2.3, 95\% CI 1.5-3.4) and decreased daily activities (OR:1.7, 95\% CI 1.1-2.6). ${ }^{27}$ In other studies, health outcomes such as diabetes mellitus were reported to be associated with visual impairment, ${ }^{28}$ or with defective physical functions such as imbalance or falls. ${ }^{29-31}$ Visual impairment at age 70 years and older significantly predicted poor self-rated health (OR 2.36, 95\% CI 1.09-5.10) and mortality, with a two-and-a-half-fold increase in risk of death at seven years (OR 2.84, $95 \%$ CI 1.48-5.46)..$^{32}$

Among causes of vision impairment, the correction of refractive errors with appropriate spectacles is among the most cost-effective interventions in eye health care. ${ }^{33}$ Similar findings, also in Asia, noted that low educational level is associated with a higher prevalence of early onset vision impairment in the population. 34,35

One of the main strengths of our study is its large size and high level of participation in a complex and detailed assessment of health and an array of geodemographic environmental and social attributes. We note the extent of vision impairment among the Thai adults but because our study is based on educated Thais; the true magnitude of the vision impairment might be even greater in the general population. Also, another limitation is the crosssectional nature of the analysis of associations between vision impairment exposures and health outcomes. Future longitudinal analysis of this Thai cohort will provide better insights into causal pathways between vision impairment and health.

Since the establishment of the Thai Universal Health Coverage Scheme, there has been an increase in the role of community health centres in responding to disparities in visual health. ${ }^{36}$ There is now a need to evaluate the eye health program and to promote further development of eye health care services, which will lead to increased availability and affordability. The results presented in this paper highlight the burden of adverse health outcomes associated with vision impairments and the need to support programmatic interventions to promote vision health among Thais.

\section{Acknowledgements and Funding}

This study was supported by the International Collaborative Research Grants Scheme with joint grants from the Wellcome Trust UK (GR071587MA) and the Australian NHMRC (268055). We thank the staff at Sukhothai Thammathirat Open University (STOU) who assisted with student contact and the STOU students who are participating in the cohort study. We also thank Dr Bandit Thinkamrop and his team from Khon Kaen University for guiding us successfully through the complex data processing. 


\section{References}

1. Resnikoff S, Pascolini D, Mariotti SP, Pokharel GP. Global magnitude of visual impairment caused by uncorrected refractive errors in 2004. Bull World Health Organ. 2008; 86(1):63-70. [PubMed: 18235892]

2. Nanayakkara SD. Vision-related quality of life among elders with cataract in Sri Lanka: findings from a study in Gampaha district. Asia Pac J Public Health. 2009; 21(3):303-311. [PubMed: 19443877]

3. Abas MA, Punpuing S, Jirapramupitak T, Tangchonlatip K, Leese M. Psychological wellbeing, physical impairments and rural aging in a developing country setting. Health Qual Life Outcomes. 2009; 7:66. [PubMed: 19607711]

4. Polack S, Eusebio C, Fletcher A, Foster A, Kuper H. Visual impairment from cataract and health related quality of life: results from a case-control study in the Philippines. Ophthalmic Epidemiol. 2010; 17(3):152-9. [PubMed: 20455844]

5. Wong TY, Loon SC, Saw SM. The epidemiology of age related eye diseases in Asia. Br J Ophthalmol. 2006; 90(4):506-11. [PubMed: 16547337]

6. Tsai SY, Chi LY, Cheng CY, Hsu WM, Liu JH, Chou P. The impact of visual impairment and use of eye services on health-related quality of life among the elderly in Taiwan: the Shihpai Eye Study. Qual Life Res. 2004; 13(8):1415-24. [PubMed: 15503837]

7. Rutzen AR, Ellish NJ, Schwab L, Graham PJ, Pizzarello LD, Hemady RK, et al. Blindness and eye disease in Cambodia. Ophthalmic Epidemiol. 2007; 14(6):360-6. [PubMed: 18161609]

8. Jenchitr W, Samaiporn S, Wongvejsawat S, Theerapanwat S, Pruksanusak V, Anutaraangkul W. Quality of vision and attitude of the Thai elderly toward their eye problems. Journal of Health Sciences [in Thai]. 2001; 10:607-614.

9. NSO. Survey of older persons in Thailand. National Statistical Office; Bangkok: 2007b.

10. NSO. Survey of disability in Thailand. National Statistical Office; Bangkok: 2007a.

11. Jenchitr W, Elderly Thais and eye health. Journal of Health Sciences [in Thai]. 2000; 9:573-583.

12. Appollonio I, Carabellese C, Magni E, Frattola L, Trabucchi M. Sensory impairments and mortality in an elderly community population: a six-year follow-up study. Age Ageing. 1995; 24(1):30-6. [PubMed: 7762459]

13. Wang CW, Chan CL. Psychosocial adaptation status and health-related quality of life among older Chinese adults with visual disorders. Qual Life Res. 2009; 18(7):841-51. [PubMed: 19562513]

14. Hayman KJ, Kerse NM, La Grow SJ, Wouldes T, Robertson MC, Campbell AJ. Depression in older people: visual impairment and subjective ratings of health. Optom Vis Sci. 2007; 84(11): 1024-30. [PubMed: 18043421]

15. Renaud J, Levasseur M, Gresset J, Overbury O, Wanet-Defalque MC, Dubois MF, et al. Healthrelated and subjective quality of life of older adults with visual impairment. Disabil Rehabil. 2010; 32(11):899-907. [PubMed: 19860601]

16. Wang JJ, Mitchell P, Smith W. Vision and low self-rated health: the Blue Mountains Eye Study. Invest Ophthalmol Vis Sci. 2000; 41(1):49-54. [PubMed: 10634600]

17. Noran NH, Izzuna MG, Bulgiba AM, Mimiwati Z, Ayu SM. Severity of visual impairment and depression among elderly Malaysians. Asia Pac J Public Health. 2009; 21(1):43-50. [PubMed: 19124335]

18. Rahi JS, Cumberland PM, Peckham CS. Visual function in working-age adults: early life influences and associations with health and social outcomes. Ophthalmology. 2009; 116(10): 1866-71. [PubMed: 19560208]

19. Caban AJ, Lee DJ, Gomez-Marin O, Lam BL, Zheng DD. Prevalence of concurrent hearing and visual impairment in US adults: The National Health Interview Survey, 1997-2002. Am J Public Health. 2005; 95(11):1940-2. [PubMed: 16195516]

20. Lam BL, Lee DJ, Gomez-Marin O, Zheng DD, Caban AJ. Concurrent visual and hearing impairment and risk of mortality: the National Health Interview Survey. Arch Ophthalmol. 2006; 124(1):95-101. [PubMed: 16401790] 
21. Sleigh AC, Seubsman SA, Bain C. Cohort profile: The Thai Cohort of 87,134 Open University students. Int J Epidemiol. 2008; 37(2):266-72. [PubMed: 17911153]

22. Andrews G, Slade T. Interpreting scores on the Kessler Psychological Distress Scale (K10). Aust N Z J Public Health. 2001; 25(6):494-7. [PubMed: 11824981]

23. Yiengprugsawan V, Hogan A, Harley D, Seubsman S, Sleigh AC. Epidemiological associations of hearing impairment and health among a national cohort of 87134 adults in Thailand. Asia Pac J Public Health. 2011 published online before print May 5, 2011(doi: 10.1177/1010539511408712).

24. Webb, P.; Bain, C.; Pirozzo, S. Essential epidemiology: an introduction for students and health professionals. Cambridge University Press; New York, NY: 2005.

25. Singalavanija A, Metheetrairut A, Ruangvaravate N, Tuchinda R, Wanumkarng N. Ocular diseases and blindness in elderly Thais. J Med Assoc Thai. 2001; 84(10):1383-8. [PubMed: 11804245]

26. Yingyong P. Evaluation of the Thai, Low Vision Quality-of-Life Questionnaire (LVQOL). J Med Assoc Thai. 2007; 90(12):2658-61. [PubMed: 18386717]

27. Carabellese C, Appollonio I, Rozzini R, Bianchetti A, Frisoni GB, Frattola L, et al. Sensory impairment and quality of life in a community elderly population. J Am Geriatr Soc. 1993; 41(4): 401-7. [PubMed: 8463527]

28. Zhang X, Gregg EW, Cheng YJ, Thompson TJ, Geiss LS, Duenas MR, et al. Diabetes mellitus and visual impairment: national health and nutrition examination survey, 1999-2004. Arch Ophthalmol. 2008; 126(10):1421-7. [PubMed: 18852421]

29. Harwood RH, Foss AJ, Osborn F, Gregson RM, Zaman A, Masud T. Falls and health status in elderly women following first eye cataract surgery: a randomised controlled trial. $\mathrm{Br} \mathbf{J}$ Ophthalmol. 2005; 89(1):53-9. [PubMed: 15615747]

30. Gerson LW, Jarjoura D, McCord G. Risk of imbalance in elderly people with impaired hearing or vision. Age Ageing. 1989; 18(1):31-4. [PubMed: 2711920]

31. Thiamwong L, Thamarpirat J, Maneesriwongul W, Jitapunkul S. Thai falls risk assessment test (Thai-FRAT) developed for community-dwelling Thai elderly. J Med Assoc Thai. 2008; 91(12): 1823-31. [PubMed: 19133516]

32. Jacobs JM, Hammerman-Rozenberg R, Maaravi Y, Cohen A, Stessman J. The impact of visual impairment on health, function and mortality. Aging Clin Exp Res. 2005; 17(4):281-6. [PubMed: 16285193]

33. Ferraro JG, Mazzoni LL, Keeffe JE, Vu HT, Constantinou M, Taylor HR. Evaluation of an eye health program: the vision initiative. Ophthalmic Epidemiol. 2006; 13(2):127-35. [PubMed: 16581617]

34. Liu JH, Cheng CY, Chen SJ, Lee FL. Visual impairment in a Taiwanese population: prevalence, causes, and socioeconomic factors. Ophthalmic Epidemiol. 2001; 8(5):339-50. [PubMed: 11922386]

35. Cackett P, Tay WT, Aung T, Wang JJ, Shankar A, Saw SM, et al. Education, socio-economic status and age-related macular degeneration in Asians: the Singapore Malay Eye Study. Br J Ophthalmol. 2008; 92(10):1312-5. [PubMed: 18664503]

36. Proser M, Shin P. The role of community health centers in responding to disparities in visual health. Optometry. 2008; 79(10):564-75. [PubMed: 18922492] 
Table 1

Cohort characteristics of cohort members by types of vision impairments, 2009

\begin{tabular}{|l|c|c|c|c|}
\hline Characteristics & \multicolumn{3}{|c|}{ Percent prevalence (n) by vision impairment categories } \\
\hline & $\begin{array}{c}\text { Refractive errors } \\
\text { since childhood }\end{array}$ & $\begin{array}{c}\text { Refractive errors } \\
\text { since adolescence }\end{array}$ & $\begin{array}{c}\text { Refractive errors } \\
\text { since adulthood }\end{array}$ & $\begin{array}{c}\text { Not correctable by } \\
\text { visual aids }\end{array}$ \\
\cline { 2 - 6 } Total & $1.3(1,121)$ & $5.7(4,944)$ & $21.1(18,364)$ & $7.9(6,859)$ \\
Males & $1.0(410)$ & $3.7(1,440)$ & $19.3(7,627)$ & $7.9(3,123)$ \\
Females & $1.5(711)$ & $7.4(3,504)$ & $22.5(10,735)$ & $7.8(3,736)$ \\
15-19 years & $2.0(49)$ & $10.8(270)$ & $2.1(53)$ & $4.8(121)$ \\
20-29 years & $1.4(607)$ & $6.5(2,887)$ & $14.8(6,527)$ & $6.7(2,960)$ \\
30-39 years & $1.2(331)$ & $4.2(1,157)$ & $18.5(5,039)$ & $8.7(2,380)$ \\
$40-49$ years & $1.1(124)$ & $4.7(519)$ & $47.6(5,211)$ & $10.4(1,135)$ \\
250 years & $0.5(10)$ & $5.1(110)$ & $71.1(1,529)$ & $12.2(262)$ \\
<7000 Baht/month & $1.3(455)$ & $5.6(1,987)$ & $13.5(4,824)$ & $7.1(2,530)$ \\
$7000-10000$ Baht/month & $0.9(180)$ & $4.6(917)$ & $19.6(3,951)$ & $8.2(1,616)$ \\
$>10000$ Baht/month & $1.6(463)$ & $6.5(1,909)$ & $31.4(9,268)$ & $8.6(2,554)$ \\
Rural residents & $0.6(247)$ & $3.7(1,409)$ & $17.2(6,505)$ & $7.8(2,948)$ \\
Rural-urban & $0.7(182)$ & $4.0(1,091)$ & $24.0(6,588)$ & $6.7(1,155)$ \\
Urban residents & $3.2(692)$ & $11.1(2,444)$ & $24.0(5,271)$ & $8.6(2,348)$ \\
\hline
\end{tabular}


Table 2

Prevalence of selected health outcomes by types of vision impairments (\%)

\begin{tabular}{|c|c|c|c|c|}
\hline \multirow[t]{3}{*}{ Outcomes } & \multicolumn{4}{|c|}{ Percent prevalence (n) by vision impairment categories } \\
\hline & \multicolumn{2}{|c|}{$\%$ Refractive vision impairment } & \multicolumn{2}{|c|}{ \% Not correctable by visual aids* } \\
\hline & \begin{aligned} & \multicolumn{1}{c}{ no } \\
$(\mathrm{n}= & \mathbf{6 2 , 7 0 5 )})\end{aligned}$ & $\begin{array}{c}\text { yes } \\
(n=24,429)\end{array}$ & $\begin{array}{c}\text { no } \\
(\mathbf{n}=\mathbf{8 0 , 2 7 5 )}\end{array}$ & $\begin{array}{c}\text { yes } \\
(\mathbf{n}=\mathbf{6 , 8 5 9})\end{array}$ \\
\hline Poor self-assessed health & $4.0(2,517)$ & $6.0(1,469)$ & $4.3(3,448)$ & $7.8(538)$ \\
\hline Poor psychological health & $5.6(3,491)$ & $6.9(1,676)$ & $5.7(4,559)$ & $8.9(608)$ \\
\hline Poor hearing & $7.2(4,506)$ & $12.2(2,988)$ & $8.1(6,525)$ & $14.1(969)$ \\
\hline Metabolic disorders & $6.9(4,323)$ & $14.8(3,623)$ & $8.9(7,116)$ & $12.1(830)$ \\
\hline Overall injuries in 12 months & $21.7(13,581)$ & $21.1(5,152)$ & $21.0(16,839)$ & $27.6(1,894)$ \\
\hline Falls & $4.2(2,633)$ & $4.8(1,175)$ & $4.3(3,414)$ & $5.7(394)$ \\
\hline
\end{tabular}


Table 3

Adjusted Odds Ratios (ORs) and Confidence Intervals (CI) for types of vision impairments and selected health outcomes among cohort members*

\begin{tabular}{|lcccc|}
\hline Health outcomes & \multicolumn{2}{c}{ Refractive errors } & \multicolumn{2}{c}{ Uncorrectable vision impairment } \\
\hline & Odds Ratio & $\mathbf{9 5 \% ~ C I ~}$ & Odds Ratio & $\mathbf{9 5 \% ~ C I ~}$ \\
Poor self-assessed health & 1.23 & $1.32-1.55$ & 2.03 & $1.83-2.25$ \\
Poor psychological health & 1.13 & $1.04-1.22$ & 1.63 & $1.46-1.81$ \\
Overall injuries in 12 months & 1.00 & $0.96-1.05$ & 1.42 & $1.34-1.51$ \\
Falls in the last 12 months & 1.08 & $1.00-1.18$ & 1.41 & $1.27-1.59$ \\
\hline
\end{tabular}

* The reference group was all persons who have neither type of vision impairment; each OR is adjusted for age, sex, income, lifecourse urbanization, poor hearing, and metabolic disorders. 
Table 4

Population Attributable Fractions (PAF) by selected health outcomes

\begin{tabular}{|l|c|c|c|c|}
\hline & \multicolumn{4}{|c|}{ PAF (\%) by health outcomes } \\
\cline { 2 - 5 } Types of vision impairment & $\begin{array}{c}\text { Poor self-assessed } \\
\text { health }\end{array}$ & $\begin{array}{c}\text { Poor psychological } \\
\text { health }\end{array}$ & Overall injuries & Falls \\
\hline $\begin{array}{l}\text { Refractive errors } \\
\text { Not correctable by any } \\
\text { visual aids }\end{array}$ & 6.1 & 3.5 & 0.3 & 2.2 \\
& 7.5 & 4.7 & 3.2 & 3.1 \\
\hline
\end{tabular}

* PAF estimates the proportion of the disease or condition that would not occur if no one in the population had the risk factor. For example, $6.1 \%$ of poor self-assessed health noted in the cohort would not occur if there were no refractive errors in the population. 